\title{
Applicability of Cytological Grading of Carcinoma Breast
}

\author{
Saroj Pachori ${ }^{1}$, Kriti Chaturvedi², Geeta Pachori ${ }^{3 *}$, Tarun Tiwari and Disha Jain ${ }^{2}$ \\ ${ }^{1}$ Department of Pathology, Sawai Man Singh Medical College, Jaipur (Rajasthan) \\ ${ }^{2}$ Department of Pathology, Jawahar Lal Nehru Medical College, Ajmer (Rajasthan) \\ ${ }^{3}$ Department of Respiratory Medicine and TB, Jawahar Lal Nehru Medical College, Ajmer (Rajasthan)
}

\section{ABSTRACT}

Background: In India breast cancer incidence is on rise and large number of cases occur before 50 years of age. Early diagnosis and proper treatment are known to increase the survival of the patients. As fine needle aspiration cytology is widely used as a preliminary mode for the diagnosis of breast malignancies, adding a reliable grading system in reporting shall aid in planning the management options.

Methods: It's a prospective study done on 100 cases of breast malignancies from June 2018 to May 2020 in department of Pathology JLNMC, Ajmer. Cytology smears were stained with H\&E and Geimsa and graded according to Robinson's cytological grading system while their corresponding histopathological sections were stained with H\&E and graded as per Elston and Ellis modification of Scarff Bloom \& Richardson grading system and the results were compared.

Result: Out of 100 cases of breast cancer evaluated in cytology $29 \%$ were grade I, $56 \%$ were grade II and $15 \%$ were grade III. On histopathological evaluation $25 \%$ were grade I, $54 \%$ were grade II while $21 \%$ were grade III. A highly significant association between the two grading systems was observed with coefficient of correlation 0.831 , p value of $<0.001$ and concordance rate $80 \%$.

Conclusion: There is high degree of concordance between the Robinson's and Elston and Ellis modification of Scarff Bloom \& Richardson grading system. Robinson's method is an easy and quick and reliable method to grade carcinomas of breast, hence it should be included in cytology reporting of breast carcinomas.

Keywords: FNAC, H\&E, MBR

\section{Introduction}

Breast cancer is now vastly spread in both developed (794,000 cases) and developing regions (883,000 cases). It is the most common cancer among women, consisting of about $25 \%$ of all cancers (about 1.67 million newly diagnosed cases in 2012). It is the fifth most common cause of mortality from cancer, but mortality rate is much higher in developing regions. ${ }^{[1]}$

It 2012, about 144,937 new cases of breast cancers were diagnosed in India, which accounts for $27 \%$ of cancer cases along with mortality of $21.5 \%$ of all cancer cases. ${ }^{[2]}$

Breast cancer grade is a major determinant of prognosis. Fine-needle aspiration cytology (FNAC) which is widely used for the diagnosis of breast malignancies before planned surgery, is used only to differentiate benign from malignant and the morphology of tumour. ${ }^{[3]}$

The assessment of grading in cytology allows assessment of the tumor in situ which facilitates in deciding the most suitable treatment. Also, overtreatment of low-grade tumors can be avoided hence reduces the post treatment morbidity. ${ }^{[4]}$
Such grading would allow assessment of the tumor in situ, and the morbidity associated with over-treatment of lowgrade tumors could be avoided. ${ }^{[4]}$

The grade predicts the outcome or prognosis. A lower grade usually means the cancer is slower-growing and less likely to spread. A higher grade means an aggressive tumour. ${ }^{[5]}$

Treatment is mainly determined by the Stage of tumour but as neoadjuvant therapy is now an integral part of primary treatment of breast cancer it makes grading of the neoplasm even more important than before by fine-needle aspiration cytology (FNAC). It is commonly done for early breast cancer, so knowledge about grade of the tumor before surgery is desirable. ${ }^{[6]}$

Cytological grading of breast cancer is not routinely done although grade of carcinoma is a widely evaluated entity in pathological specimens. ${ }^{[6]}$

Various cytological grading systems are: Robinson's, Mouriquand's, Hunt's, Simplified black's, Fisher's modification of black's nuclear grading, Khan's. 


\section{Materials and Methods}

This is a prospective study of two-year duration from June 2018 to May 2020 conducted in department of pathology JLN Medical College Ajmer (Rajasthan).

Study material comprised of 100 cases of mastectomy specimens received in the department and their corresponding cytology smears. Written informed consent was taken from all patients.

Sections were stained with Hematoxylin \& Eosin and Smears were stained with Hematoxylin \& Eosin and May Grunwald Giemsa; special stains were done wherever required.

On FNAC smears Robinson's cytological grading system ${ }^{[7-10]}$ (Table 1) was used and on their corresponding histopathology sections Elston and Ellis modification of Scarff Bloom \& Richardson grading system ${ }^{[11-14]}$ (Table 2) was used and the results were correlated.

\section{Result}

In the present study out of total 100 cases maximum cases $(56 \%)$ belong to cytological grade II, followed by $29 \%$ cases in cytological grade I and least percentage of cases $(15 \%)$ belonged to cytological grade III. While on histological examination 54\% cases belong to Grade II, followed by $25 \%$ cases in histological grade I and least percentage of cases $(21 \%)$ belonged to histological grade III.

Out of 29 cases of cytological Grade I, 25 cases correlated with histological Grade I and remaining 4 cases were

Table 1: Robinson's cytological grading system ${ }^{\text {7-10 }}$

\begin{tabular}{|l|l|l|l|}
\hline Criterion & Score 1 & Score 2 & Score 3 \\
\hline Cell dissociation & Mostly cluster & Single cells, cluster & Mostly single cells \\
\hline Nuclear size & 1-2 times size of RBC & 3-4 times size of RBC & $>$ /=5 times of RBC \\
\hline Cell uniformity & Monomorphic & Mildly pleomorphic & Pleomorphic \\
\hline Nucleoli & Indistinct /Small & Noticeable & Abnormal \\
\hline Nuclear margin & Smooth & Slightly irregular/folds & Buds, clefts \\
\hline Chromatin pattern & Vesicular & Granular & Clumping/clearing \\
\hline Grade I : Score 6-11 & Grade II : Score 12-14 & Grade III :Score 15-18 & \\
\hline
\end{tabular}

Table 2: Elston and Ellis modification of Scarff Bloom Richardson grading system ${ }^{11-14}$

\begin{tabular}{|l|l|l|}
\hline & Feature & Feature score \\
\hline $\mathbf{I}$ & Percent tubule formation (extent within tumour) & \\
\hline & $>75 \%$ & 1 \\
\hline & $10-75 \%$ & 2 \\
\hline II & $<10 \%$ & 3 \\
\hline & Nuclear pleomorphism & \\
\hline & Small, regular, uniform cells & 1 \\
\hline & Moderate variation in size and shape & 2 \\
\hline & Marked variation in size and shape & 3 \\
\hline
\end{tabular}

upgraded as Grade II. Out of 56 cases of cytological Grade II, 45 cases correlated with histological Grade II and remaining 11 cases were upgraded as Grade III. Out of 15 cases of cytological Grade III, 10 cases correlated with histological Grade III and remaining 5 cases were downgrade as Grade II on histology.

The highest concordance rate between cytological and histological grade was found in Grade I tumors (86.2\%) followed Grade II tumors (80.3\%) and least in Grade III tumors $(66.7 \%)$, Out of 100 cases 80 cases showed agreement between the respective cytological and histological grades. Absolute concordance rate was $80 \%$.

A significant statistical association between the grades assigned to cytologic and histologic specimens was observed $(\mathrm{r}=0.831, \mathrm{p}<0.001)$.

Sensitivity of Robinson's cytological grading system was maximum in cytological Grade I tumors $(100 \%)$, followed by Cytological Grade II tumors (83.3\%) and least in cytological Grade III tumors (47.6\%).

Specificity of Robinson's cytological grading system was similar in cytological Grade I and Grade III tumors (94.6\% and $93.7 \%$ respectively) and least in cytological Grade II tumors $(76.09 \%)$.

Multiple regression analysis of cytological features with histological grade showed that all of the features included in Robinson's cytological grading system were statistically significant $(\mathrm{p}=0.000)$ and all of them equally contributed in determining the histologic grade of the tumor. 


\begin{tabular}{|l|l|l|}
\hline & Feature & Feature score \\
\hline III & Mitotic count per 10 high-power fields(hpf) & \\
\hline & $0-5$ mitoses/10hpf & 1 \\
\hline & $6-11$ mitoses/10hpf & 2 \\
\hline & $>/=12$ mitoses/10hpf & 3 \\
\hline Histologic grade & Histologic type & Total Score \\
\hline Grade-I & Well differentiated & $3-5$ \\
\hline Grade-II & Moderately differentiated & $6-7$ \\
\hline Grade-III & Poorly differentiated & $8-9$ \\
\hline
\end{tabular}

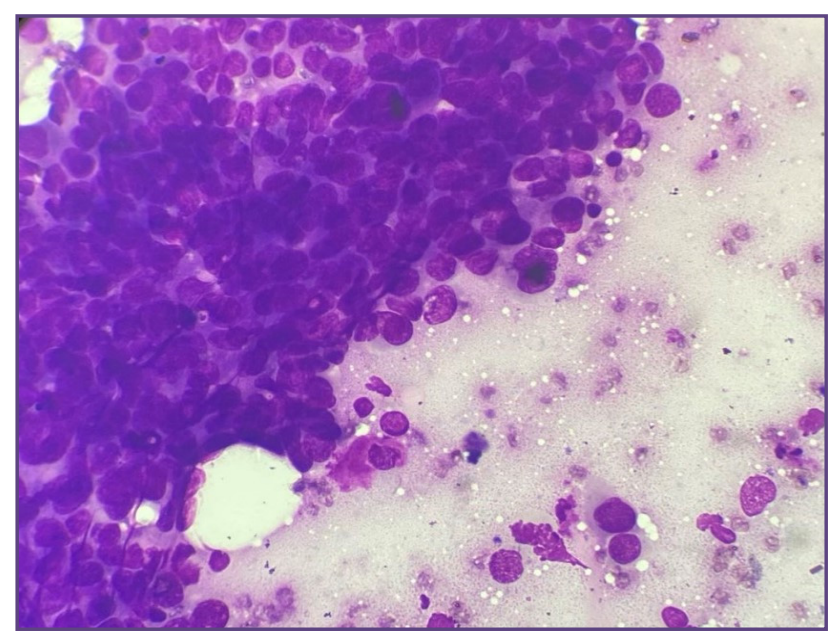

Fig. 1: FNAC Ductal carcinoma breast (Robinson's cytological grade I): Malignant epithelial cells arranged in clusters, mild pleomorphism, regular nuclear membrane, nuclear size 1-2 time of RBCs, vesicular chromatin and nucleoli indistinct noted. Cytological score 6. Giemsa stain 400x.

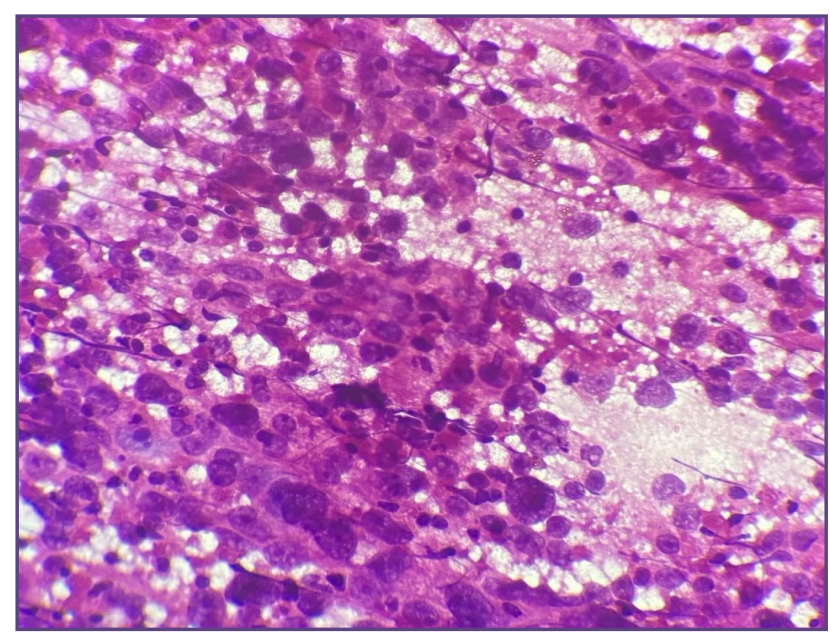

Fig. 3: FNAC Ductal carcinoma breast (Grade II): Malignant epithelial cells arranged singly with size 3-4 times size of RBC , moderate pleomorphism, noticeable nucleoli, irregular nuclear membrane and vesicular chromatin noted. Cytologic score12. H\&E 400x

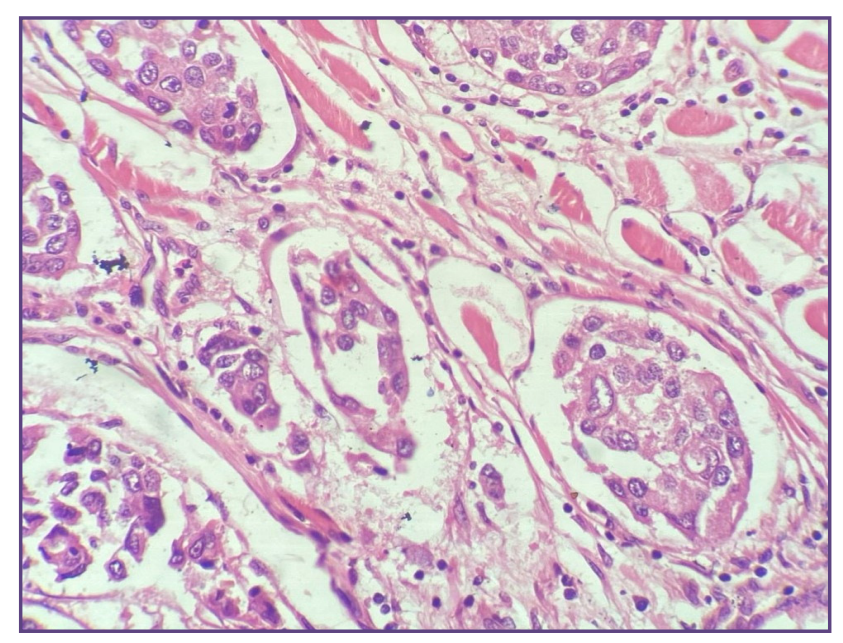

Fig. 2: Infiltrating ductal carcinoma breast (MBR grade I): Shows tubule formation in $>75 \%$ tumor mass with moderate pleomorphism and mitosis $7 / 10 \mathrm{hpf}$. MBR score 5. H\&E 400x.

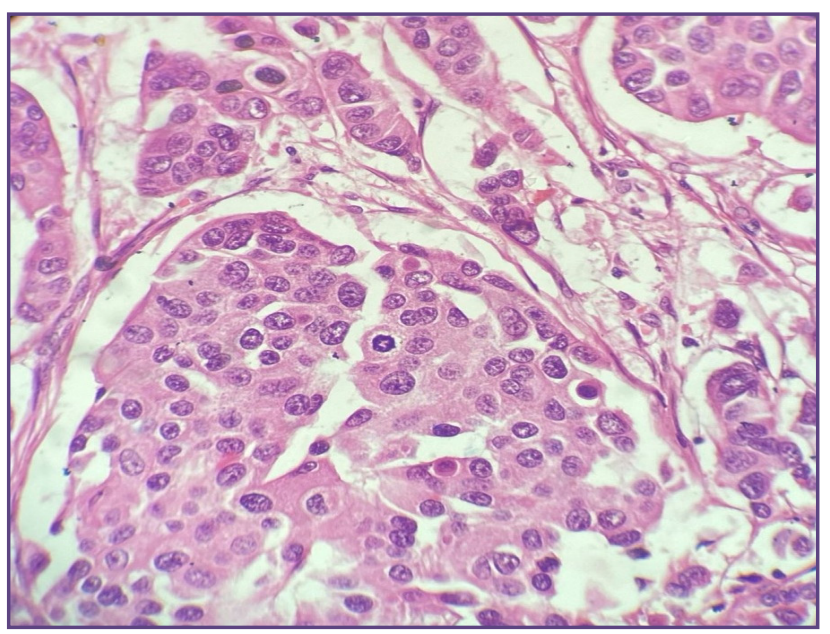

Fig. 4: Infiltrating ductal carcinoma breast (MBR grade II): Shows tubule formation in $\mathbf{1 0 - 7 5 \%}$ tumor mass with moderate pleomorphism and mitosis 13/10hpf. MBR score 7. H\&E 400x 


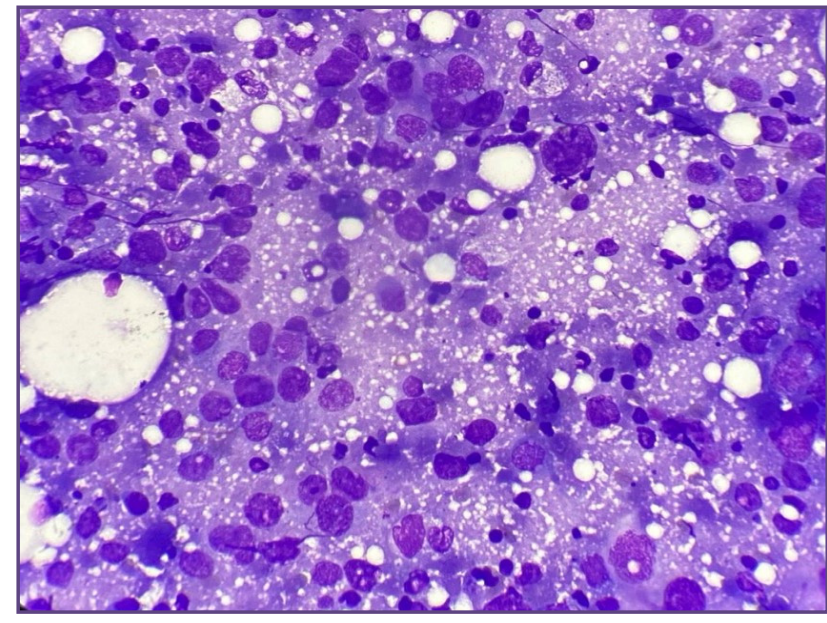

Fig. 5: FNAC Ductal carcinoma breast (Robinson's cytologic grade III): Malignant epithelial cells lying singly with marked pleomorphism, size> 5 times the size of RBC, noticeable nucleoli, irregular nuclear margin and granular chromatin noted. Cytologic score 15. Giemsa 400x.

\section{Discussion}

Fine-needle aspiration cytology is a routine investigation done globally for diagnosis of carcinoma breast from many decades. But even now it's use is limited only for providing diagnosis and morphologic type of carcinoma. Grade of breast carcinoma has prognostic implications and knowledge of the grade of tumor before planning for line of treatment can be a boon to the patient. Many systems for grading systems have been suggested over the years, but none of them have been successfully implemented in routine cytology reporting.

In this study the concordance rate between the cytological grade using Robinson's system and histological grade was $80 \%$, which is comparable to that reported by previous studies done by Das AK et al ${ }^{[15]}(71.2 \%)$, Rekha TS et al $^{[16]}(82 \%)$, Pandya AN et al ${ }^{[17]}(74.5 \%)$, Teronpi et al ${ }^{[18]}$ $(93.3 \%)$.

A statistically significant correlation between the cytological and histological grade with a Spearman correlation coefficient $\mathrm{r}=0.831$ and $P$ value of $<0.001$. Similar to studies done by Sinha A et al ${ }^{[3]}(\mathrm{r}=0.97, \mathrm{p}<0.01)$ and Pal S et al ${ }^{[19]}(\mathrm{r}=0.804, \mathrm{p}-0.000)$.

Concordance rates of individual cytological grades were $86.2 \%, 80.3 \%$ and $66.6 \%$ for Grade I, II and III respectively. So, Grade I showed highest concordance rate with histological grade, while Grade III showed lowest concordance in our study. Similar observations were made by Sood $\mathrm{N}$ et al ${ }^{[20]}$ with concordance rate of $75.0 \%, 70.6 \%$ and $60.0 \%$ for cytological Grade I, II and III tumors.

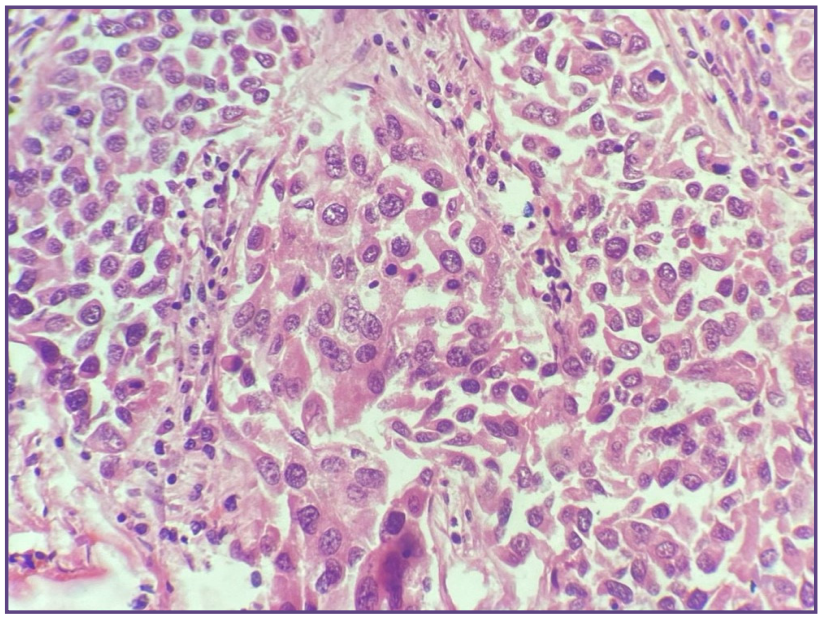

Fig. 6: Infiltrating ductal carcinoma breast (MBR grade III): Shows tubule formation in $<10 \%$ tumor mass, marked pleomorphism and mitosis 14/10hpf. MBR score 9. H\&E 400x.

In the present study, we found sensitivities for cytological grade I, II, and III tumors as 100\%, 83.3\%, and 47.6\% respectively. Pal S et al ${ }^{[19]}$ reported a similar finding of lowest sensitivity of cytological grade III tumors (45.45\%) as compared to $100 \%$ for cytological grade I and $82.14 \%$ for cytological grade II tumors.

\section{Conclusion}

There is a high degree of concordance between Robinson's and Elston and Ellis modification of Scarff Bloom \& Richardson grading system. So, Robinson's grading system should be included in routine reporting of breast carcinoma to aid in deciding proper line of treatment, as well as to avoid over-treatment and its associated morbidity in low grade carcinomas. This system is easy, takes little amount of time and is reproducible.

\section{Acknowledgements}

Dr. Geeta Pachori, Senior Professor, Department of Pathology, Jawaharlal Nehru Government Medical College, Ajmer (Rajasthan)

\section{Funding}

None

\section{Competing Interests}

None Declared

\section{Reference}

1. GLOBOCAN 2008 FACT SHEET 2010, Breast cancer incidence and mortality worldwide 2008 summary.

2. GLOBOCAN 2008, World fact sheet, 2012, 2010, section of cancer information, international agency for research on cancer, Lyon, France. 
3. Sinha A, Gill SS. Correlative study of cytological features in grading of invasive breast carcinoma. J Cytol 2018;35:14952.

4. Srivastava P, Kumar B, Joshi U, Bano M. To evaluate the applicability of parameters of cytological grading systems on aspirates of breast carcinoma. J Cytol 2018;35:15-21.

5. 1. Breast Cancer Grades | Grading Breast Cancer [Internet]. Cancer.org. 2021 [cited 23 July 2021]. Available from: https:// www.cancer.org/cancer/breast-cancer/understanding-abreast-cancer-diagnosis/breast-cancer-grades.html

6. Jyothi B. Lingegowda et al. Cytohistological Correlation of Grading in Breast Carcinoma. Diagnostic Cytopathology, Vol 39, No 4.

7. Kocjan, Gabrijela., Gray, Winifred. Diagnostic Cytopathology E-Book: Expert Consult: Online and Print. United Kingdom: Elsevier Health Sciences, 2010.

8. Robles-Frias A, Gonzalez-Campora R, Martinez-Parra D, Robles-Frias M, Vazquez-Cerezuda T, Otal-Salaverri C, et al. Robinson cytologic grading of invasive ductal breast carcinoma. Correlation with histologic grading and regional lymph node metastasis. Acta Cytol 2005;49:149-53.

9. Robinson IA, McKee G, Nicholson A, D’Arey J, Jackson PA, Cook MG, et al. Prognostic value of cytological grading of fine-needle aspirates from breast carcinomas. Lancet 1994;343:947-49.

10. Chhabra S, Singh PK, Agarwal A, Bhagolival A, Singh SN. Cytological grading of breast carcinoma-A multivariate regression analysis. J Cytol 2005;22:62-5.

11. Elston CW, Ellis IO. Pathological prognostic factors in breast cancer. The value of histological grade in breast cancer:experience from a large study with long-term follow up. Histopathology 1990;19:403-10

12. Howell LP, Gandour-Edwards R, O'Sullivan D. Application of the Scarff-Bloom-Richardson tumor grading system to fine needle aspirates of the breast. Am J Clin Pathol 1994;101:262-265.

13. Pandya A et al. Comparative evaluation of robinson's cytological grading with elston and ellis' nottingham modification of bloom richardson histopathology grading for breast carcinoma. National Journal of Community Medicine

14. Chalsie S. et al, Correlation between Robinson's cytological grading with Modiied Bloom-Richardson histopathological grading for Breast carcinoma. Journal of Pathology of Nepal (2015) Vol. 5, 791 -797

15. Das AK, Kapila K, Dinda AK, Verma K. Comparative evaluation of grading of breast carcinomas in fine needle aspirates by two methods. Indian J Med Res. 2003;118:24750.

16. Rekha TS, Nandini NM, Dhar M. Validity of different cytological grading systems of breast carcinoma - a hospital-based study in South India. Asian Pac J Cancer Prev. 2011;12:3013-6.

17. Pandya AN, Shah NP. Comparative evaluation of Robinson's cytological grading with Elston and Ellis' Nottingham Modification of Bloom Richardson histopathology grading for breast carcinoma. Natl J Community Med. 2012;3:4915. systems in breast carcinoma. J Cytol. 2013;30:87-93.

18. Teronpi Jasmine, Reena Kouli. Comparative study of fine needle aspiration cytology and histopathology in grading breast carcinoma. International Journal of Contemporary Medical Research 2019;6(7):G21-G25.

19. Pal S, Gupta ML. Correlation between cytological and histological grading of breast cancer and its role inprognosis. J Cytol 2016;33:182-6.

20. Sood N et al. Comparative Study of Cytomorphological Robinson's Grading for Breast Carcinoma with Modified Bloom-Richardson Histopathological Grading. Hindawi Publishing Corporation Pathology Research International Volume 2013

*Corresponding author:

Dr. Geeta Pachori, Postal Address: 215/12, Rajendra Pura, Hathi Bhata, Ajmer (Rajasthan)- 305001

Phone: +91 9414006613

Email: dr.geeta.pachori@gmail.com

Financial or other Competing Interests: None.

$\begin{array}{lr}\text { Date of Submission } & : 10 / 03 / 2021 \\ \text { Date of Final Revision } & : 14 / 07 / 2021 \\ \text { Date of Acceptance } & : 18 / 07 / 2021 \\ \text { Date of Publication } & : 30 / 07 / 2021\end{array}$ 